REVISTA VIRTUAL VIA INVENIENDI ET IUDICANDI

"CAMINO DEL HALLAZGO Y DEL JUICIO"

http://viei.usta.edu.co/ E-MAIL: revistainveniendi@usantotomas.edu.co

\title{
LA ELECCIÓN DIRECTA DE PARLAMENTARIOS ANDINOS
}

\section{THE DIRECT ELECTION OF ANDEAN PARLAMENTARIES}

\begin{abstract}
CAROLINA BLANCO ALVARADO
Docente Facultad de derecho Universidad Santo Tomas / Abogada de la Universidad Externado de Colombia / Especialista en Derecho Administrativo Universidad del Rosario / Especialista en Derecho Constitucional / Centro de Estudios Políticos y Constitucionales de Madrid - España / Magister en Derechos Fundamentales Universidad Carlos III de Madrid - España / Email carolinablancoalvarado@hotmail.com
\end{abstract}

Fecha de recepción: 10 de octubre de 2009. Fecha de aprobación: 5 de abril de 2010.

\section{Resumen:}

En un mundo globalizado los procesos de integración vienen tomando cada día más fuerza; lo que implica mayor participación democrática de los actores políticos y sociales, situación que todavía no se evidencia en el Proceso de Integración Andino y que aspira lograrse mediante la consolidación de las elecciones directas y universales de parlamentarios andinos.

El Parlamento Andino está llamado a convertirse en la columna vertebral del proceso de integración en suramericana. Por lo tanto, es indispensable que los países miembros de la Comunidad Andina (CAN), respalden mediante la elección 
directa, la consolidación y legitimación del órgano representante de los ciudadanos andinos en el contexto supranacional.

\section{Abstract :}

In a globalized world integration processes are taking more and more strength, which implies greater democratic participation in political and social actors, a situation that is not yet evident in the Andean integration process and aims achieved through the consolidation of elections direct and universal Andean Parliament.

The Andean Parliament is called to become the backbone of South American integration process. Therefore, it is essential that the member countries of the Andean Community (CAN), support through the direct election of their representatives to consolidate and legitimate representative organ of the Andean citizens in the supranational context.

\section{Palabras clave:}

Integración Andina, Parlamento Andino, Democracia

\section{Key words:}

Andean Integration, the Andean Parliament, Democracy 


\section{Identificación del Artículo:}

Reflexión académica.

\section{INTRODUCCIÓN:}

Mediante el presente escrito, fundamentado principalmente, en normas internacionales regulatorias de la Comunidad Andina (CAN), jurisprudencia de la Corte Constitucional Colombiana y literatura relacionada con el derecho de la integración, se pretende formular algunas soluciones a la crisis que atraviesa la Integración Andina, las cuales si se quisieren sintetizar estarían fundamentadas en la necesidad de la consolidación de la elección directa de parlamentarios andinos en los Estados que integran a la Comunidad Andina.

\section{CONTEXTUALIZACIÒN DEL PARLAMENTO ANDINO}

La Comunidad Andina surgió como una necesidad de los países miembros (Bolivia, Colombia, Ecuador, Perú y Venezuela) de instaurar un sistema de integración de sus intereses económicos, destinado a lograr el desarrollo equilibrado y armónico de la subregión y de acelerar su crecimiento, mediante la armonización de sus políticas económicas y la coordinación de los planes de 


\section{REVISTA VIRTUAL VIA INVENIENDI ET IUDICANDI}

"CAMINO DEL HALLAZGO Y DEL JUICIO"

http://viei.usta.edu.co/ E-MAIL: revistainveniendi@usantotomas.edu.co

desarrollo ${ }^{1}$. En este sentido, la realización del proyecto de integración reclamó la estructuración y puesta en funcionamiento de una organización administrativa y técnica y determinó la creación de autoridades comunitarias, con específicas competencias, y del mismo modo, la formulación de un sistema normativo con el vigor y la eficacia requeridos para que aquéllas pudieran regular directamente las cuestiones atinentes a la materia de integración y la conducta de los países comprometidos y de sus habitantes, sin tener que recurrir a los procedimientos ordinarios del derecho interno de cada país ${ }^{2}$. En este contexto, fue creado el Parlamento Andino como el órgano comunitario deliberante de la Comunidad Andina, creado con el objeto de orientar el proceso de integración, sustentar el pleno ejercicio de la libertad y la justicia social; defender los derechos humanos; promover la participación de los pueblos; fomentar el desarrollo y contribuir al afianzamiento de la paz y la justicia internacional.

\section{MARCO NORMATIVO DE LA ELECCIÓN DIRECTA DE PARLAMENTARIOS ANDINOS}

La Constitución colombiana, prevé normas que explícitamente señalan el interés del Estado de promover la integración latinoamericana; principalmente a través de la Comunidad Andina, y en este sentido, la Carta Política, faculta al gobierno para

\footnotetext{
${ }^{1}$ Ver ACUERDO DE CARTAGENA firmado el 26 de Mayo de 1969 y aprobado por la ley 8a. de Abril 14 de 1973.

2 PEREZ TREMPS Pedro, Constitución Española y Comunidad Europea, Madrid 1994, pag 39
} 


\section{REVISTA VIRTUAL VIA INVENIENDI ET IUDICANDI}

"CAMINO DEL HALLAZGO Y DEL JUICIO"

http://viei.usta.edu.co/E-MAIL: revistainveniendi@usantotomas.edu.co

que suscriba tratados de integración sobre bases de equidad, igualdad y reciprocidad. Es por lo anterior, que resulta procedente afirmar que en Colombia existe el fundamento constitucional para avanzar, desde el punto de vista normativo, en la consolidación de la Comunidad Andina y de una Comunidad Latinoamericana ${ }^{3}$.

En atención al citado marco constitucional, el Gobierno Colombiano ha suscrito diferentes normas internacionales relacionadas con el proceso andino de integración, entre ellas, es pertinente en primera instancia hacer referencia al Tratado Constitutivo del Parlamento Andino, el cual entró en vigor en el año de 1984, luego de ser ratificado por todos los Estados Partes. En este sentido, el artículo $2^{\circ}$ del mismo, dispuso que el Parlamento Andino estaría constituido por representantes de los Estados Parte, los cuales serían elegidos por sufragio universal y directo, de conformidad con el procedimiento que los Estados Miembros adoptarán mediante Protocolo Adicional. Y en este sentido, para suplir el período en que tardaría en aprobarse y en entrar en vigencia el mencionado Protocolo Adicional, el art. $3^{\circ}$ dispuso que, en el entretanto, "el Parlamento Andino estará constituido por cinco representantes elegidos por los respectivos órganos legislativos de las Partes Contratantes, según el procedimiento que cada uno de aquellos adopte para el efecto".

\footnotetext{
${ }^{3}$ Ver al respeto la Cconstitución Política Colombiana (Artículos 9 y 227)
} 


\section{REVISTA VIRTUAL VIA INVENIENIDI ET IUDICANDI \\ "CAMINO DEL HALLAZGO Y DEL JUICIO"}

http://viei.usta.edu.co/ E-MAIL: revistainveniendi @usantotomas.edu.co

Lo dispuesto en el Tratado constitutivo con relación a la elección directa de Parlamentarios Andinos esta reiterado en el Protocolo de Trujillo, el cual entró en vigor en el año 1997. Es de relevancia anotar que dicho Protocolo previo en la disposición transitoria Séptima que "Las elecciones por sufragio universal y directo de los representantes ante el Parlamento Andino deberán realizarse dentro de un plazo de hasta cinco años."

En el año 1997, los Gobiernos de los Países Miembros aprobaron el Protocolo Adicional al Tratado Constitutivo del Parlamento Andino sobre Elecciones Directas y Universales de sus Representantes, el cual prevé los procedimientos que se deben adelantar en cada Estado Miembro para la elección mediante sufragio universal, directo y secreto de los parlamentarios andinos. Allí se insiste en que la elección popular de estos parlamentarios debe realizarse dentro un plazo máximo de cinco años (art. 1). Este último Tratado prevé que cada país elegirá cinco representantes al Parlamento Andino (art. 3) y que hasta que no se establezca un régimen electoral uniforme el sistema de elección se regirá por la legislación interna de cada país (art. 4).

Después de 10 años de suscrito el Protocolo Adicional al Tratado Constitutivo del Parlamento Andino sobre Elecciones Directas y Universales, los gobiernos de los Estados Miembros de la CAN han dado cumplimiento al mandato supranacional de reglamentar lo correspondiente a las elecciones directas y universales de sus 
representantes ante el órgano deliberante de la CAN. Para el efecto, la nueva Constitución Boliviana, promulgada en abril de 2009, prevé que "las representantes y los representantes de Bolivia ante organismos parlamentarios supraestatales emergentes de los procesos de integración se elegirán mediante sufragio universal" (Art. 267). En Colombia, a través de la ley estatutaria No. 1157 de 2007, se aprobó y reglamento internamente la elección directa de Parlamentarios Andinos para el año 2010. No sobra anotar que Ecuador y Perú, con anterioridad a Bolivia y Colombia, aprobaron por vía legal, la elección directa de Parlamentarios Andinos, lo cual ha permitido que a la fecha los Parlamentarios por los citados Estados sean elegidos por vía de elección popular y no por designación de los Congresos Nacionales, como a la fecha sucede con Bolivia y Colombia.

\section{IMPORTANCIA DE LA ELECCIÓN DIRECTA DE PARLAMENTARIOS} ANDINOS

La integración, no es un proceso exclusivamente económico, intergubernamental o interestatal. Por el contrario, necesita el concurso activo de los actores políticos y de la sociedad civil para adquirir vigencia en el marco del sistema de principios y valores aceptados por las democracias contemporáneas. La participación de la ciudadanía en el proceso de integración es un factor de legitimidad y una 


\section{REVISTA VIRTUAL VIA INVENIENDI ET IUDICANDI}

"CAMINO DEL HALLAZGO Y DEL JUICIO"

http://viei.usta.edu.co/ E-MAIL: revistainveniendi@usantotomas.edu.co

condición de éxito, como quiera que si sólo participan los gobiernos, el proceso se estanca y fracasa. En cambio, con la participación del pueblo andino, el proceso de integración se transforma en un factor de consolidación de los regímenes democráticos que en él participan.

Es precisa la existencia de un consenso del pueblo andino en el proceso de integración, lo cual se logra si se interpreta y representa la auténtica voluntad popular, lo cual genera la importancia política y jurídica de los Órganos Comunitarios del Sistema Andino de Integración, y como consecuencia de ello, mayor autonomía y poder decisorio a los mismos.

La elección directa y universal de los parlamentarios andinos es una necesidad para todos y de cada uno de los Estados Andinos, como una demostración de la voluntad de cumplimiento de sus compromisos y obligaciones internacionales, que en materia de integración andina tienen su fundamento en el Acuerdo de Cartagena de 1973, Tratado Constitutivo del Parlamento Andino de 1984, Protocolo de Trujillo de 1997 y Protocolo de elección directa de Parlamentarios Andinos de 1997. 


\section{LA CRISIS DEL PROCESO ANDINO DE INTEGRACIÓN}

Si quisiéramos sintetizar las causas de la crisis del proceso de integración andino, podemos afirmar que la misma obedece a los aspectos que a continuación se proceden a referenciar"

- Ausencia de metas claras y de estrategias frente al proceso de globalización en marcha que permitan contribuir a solucionar los graves problemas socioeconómicos que afectan los pueblos de la región. Lo anterior obedece, entre otras causas, a que actualmente, el proceso andino de integración no ofrece una agenda propia, lo cual genera que la Integración Andina se convierta en un proceso retórico, inercial y no propositivo.

- Deslegitimización del proceso andino de integración frente al pueblo andino, quien no siente que dicho proceso contribuya con soluciones a sus problemas socio-económicos.

- Desinstitucionalización del proceso andino de integración, al no ser acatados los fallos de los órganos del Sistema Andino de Integración (SAl), por la prioridad asignada a las consideraciones locales o internas de los países sobre los intereses comunitarios.

\footnotetext{
${ }^{4}$ Ver Articulo de la Ex Parlamentaria Andina Willma Salgado en la Revista "Indo América", revista de integración andina, nov 2007.
} 


\section{REVISTA VIRTUAL VIA INVENIENIDI ET IUDICANDI \\ "CAMINO DEL HALLAZGO Y DEL JUICIO"}

http://viei.usta.edu.co/ E-MAIL: revistainveniendi@usantotomas.edu.co

- Déficit democrático en el proceso andino de integración, reflejado en la inexistencia de espacios deliberativos democráticos, lo cual genera la no participación activa de los organismos del Sistema Andino de Integración en el proceso y mucho menos del pueblos andino, cuya participación, de conformidad con la normatividad internacional, debe ser promovida por el Parlamento Andino de acuerdo con los propósitos de su creación.

Otra de las manifestaciones del Déficit Democrático que padece el proceso andino de integración radica en la concentración de poder en los órganos intergubernamentales del Sistema Andino de Integración (Consejo Presidencial Andino y Consejo de Ministros de Relaciones Exteriores) y en la reducción de funciones y autonomía de los órganos de carácter comunitario (Parlamento Andino y Tribunal de Justicia de la Comunidad Andina), muestra de ello, es que el Parlamento Andino, a pesar de ser el órgano fundamental que genera el involucramiento de la sociedad civil, tiene una función básicamente declarativa y deliberativa sin ningún poder decisorio y de carácter realmente vinculante.

- La escasa voluntad política de los Estados que conforman la Comunidad Andina (CAN) de promover y fortalecer el proceso andino de integración, lo cual genera la reducción de los compromisos andinos a simples acuerdos diplomáticos. 


\section{COMO SUPERAR LA CRISIS DEL PROCESO ANDINO DE INTEGRACIÓN?}

En aras de aproximarnos a una posible solución a la crisis del proceso andino de integración, calificado incluso terminal por algunos investigadores, podemos afirmar que es necesario romper el aislamiento de las instituciones encargadas de promover la integración andina con la población de los países miembros, identificando en forma conjunta metas, estrategias y levantando una agenda que responda a las necesidades de los pueblos y dotando de legitimidad al proceso. La efectividad de la citada propuesta depende de la consolidación jurídica y política en cada uno de los Estados que conforman a la Comunidad Andina (CAN) de la elección directa de parlamentarios andinos.

A pesar de que la mayoría de los Estados Andinos han procedido con la reglamentación de la elección directa de Parlamentarios Andinos, es preciso puntualizar algunas circunstancias que no han permitido la consolidación de dicho proceso de elección:

a) En el caso de Colombia y Bolivia, Estados que a la fecha no presentan parlamentarios andinos designados por vía de elección popular, no se ha efectuado el estudio del impacto fiscal que demandará la elección popular. 


\section{REVISTA VIRTUAL VIA INVENIENIDI ET IUDICANDI \\ "CAMINO DEL HALLAZGO Y DEL JUICIO"}

http://viei.usta.edu.co/ E-MAIL: revistainveniendi @usantotomas.edu.co

Es por lo anterior que resulta pertinente que los Gobiernos de los citados países, requieran a los respectivos Ministerios de Hacienda, para que estudien y analicen el impacto fiscal que demandará la elección directa de parlamentarios andinos. Lo anterior, con la finalidad de evitar el condicionamiento en la celebración de elecciones a la destinación de recursos.

Con relación al Estado Boliviano, es pertinente anotar que si bien el articulo 267 de la Constitución Política de 2009, prevé que la designación de los miembros del Parlamento Andino se hará por vía de elección directa, a la fecha no se ha procedido con la reglamentación legal a dicha norma constitucional, esto es, no existen los procedimientos que determinen las reglas de juego para participar en la contienda electoral de designación de parlamentarios andinos, lo cual desconoce, prioritariamente, la naturaleza jurídica del derecho al sufragio. Para el efecto, es preciso recordar que constitucionalmente, las Cartas Políticas de los Estados Andinos suponen la decidida y directa protección de los Estados al derecho de sufragio, no sólo por cuanto a éstos les corresponde, como fin esencial, garantizar la efectividad de los derechos políticos de su pueblo, sino también porque el ejercicio y efectividad del citado derecho político, es presupuesto de eficacia del Estado Social de Derecho y del Estado Democrático, características constitucionales propias no solo del Estado Boliviano, sino de todos los Estados Andinos. 


\section{REVISTA VIRTUAL VIA INVENIENDI ET IUDICANDI}

"CAMINO DEL HALLAZGO Y DEL JUICIO"

http://viei.usta.edu.co/ E-MAIL: revistainveniendi@usantotomas.edu.co

Con relación al Estado Colombiano, es pertinente anotar que a pesar del gran avance en la reglamentación legal de la elección directa de parlamentarios andinos, al haberse expedido la ley estatutaria que regula dicha elección, a la fecha no existe en el presupuesto nacional del año 2010 el costo económico que generara la elección directa de Parlamentarios Andinos, esto es no existen las apropiaciones necesarias para garantizar el pago de los emolumentos y las prestaciones que corresponderán a los elegidos y los demás gastos que va a implicar elegir y tener esta representación en el Parlamento Andino.

Para el efecto, es preciso recordar que de conformidad con la jurisprudencia reiterada de la Corte Constitucional ${ }^{5}$, compete al legislador y al Presidente de la República fijar el régimen salarial y prestacional de los empleados públicos y en este sentido, la Constitución Política (Art. 150) prevé que corresponde al Congreso hacer las leyes y que por medio de ellas ejerce las siguientes funciones:

“19. Dictar las normas generales y señalar los objetivos y criterios a los cuales debe sujetarse el Gobierno para los siguientes efectos: (...)

\footnotetext{
${ }^{5}$ Ver, entre otras, las sentencias C-654 de 1997 (M.P. Antonio Barrera Carbonell), C-608 de 1999 (M.P. José Gregorio Hernández Galindo), C-292 de 2001 (M.P. Jaime Córdoba Triviño), C-835 de 2002 (M.P. Marco Gerardo Monroy Cabra), C-101 de 2003 (M.P. Jaime Córdoba Triviño).
} 


\section{REVISTA VIRTUAL VIA INVENIENDI ET IUDICANDI \\ "CAMINO DEL HALLAZGO Y DEL JUICIO" \\ http://viei.usta.edu.co/ E-MAIL: revistainveniendi @ usantotomas.edu.co}

e) Fijar el régimen salarial y prestacional de los empleados públicos, de los miembros del Congreso Nacional y de la fuerza pública."

En este orden de ideas, es el Congreso el llamado a establecer a través del procedimiento democrático de adopción de las leyes, el marco general y los objetivos y criterios que orientan al Presidente de la República para fijar el régimen salarial y prestacional de los distintos servidores públicos del Estado. En consecuencia, la definición del referenciando régimen salarial y prestacional, se desarrolla conforme al ejercicio de una competencia concurrente que corresponde, en primer lugar, al Congreso de la República y, en segundo término, al Presidente dentro del marco trazado por aquél ${ }^{6}$.

El ordenamiento jurídico colombiano prevé sin lugar a equívocos, que toda ley que implique gasto publico, debe ir avalada con el estudio del impacto fiscal, el cual deberá ser compatible con el Marco Fiscal de Mediano Plazo, determinando clara y expresamente la fuente de ingreso adicional generada para el financiamiento de dicho $\operatorname{costo}^{7}$. En este sentido, si bien, es exigencia legal el

\footnotetext{
${ }^{6}$ Ver Sentencia C-781 de 2001. M.P. Jaime Cordoba Triviño.

${ }^{7}$ La Ley 819 de 2003, por la cual se dictan normas orgánicas en materia de presupuesto, responsabilidad y transparencia fiscal, prevé en el artículo $7^{\circ}$, la obligación de analizar el impacto fiscal de todo proyecto de ley, ordenanza o acuerdo y de compatibilizarlo con el Marco Fiscal de Mediano Plazo que es elaborado por el Gobierno Nacional y aprobado por el Congreso de la República. Establece este artículo: "ARTÍCULO 7 o. ANÁLISIS DEL IMPACTO FISCAL DE LAS NORMAS. En todo momento, el impacto fiscal de cualquier proyecto de ley, ordenanza o acuerdo, que ordene gasto o que otorgue beneficios tributarios, deberá hacerse explícito y deberá ser compatible con el Marco Fiscal de Mediano Plazo. Para estos propósitos, deberá incluirse expresamente en la exposición de motivos y en las ponencias de trámite respectivas los costos fiscales de la iniciativa y la fuente de ingreso adicional generada para el financiamiento de dicho costo. El
} 


\section{REVISTA VIRTUAL VIA INVENIENDI ET IUDICANDI}

"CAMINO DEL HALLAZGO Y DEL JUICIO"

http://viei.usta.edu.co/ E-MAIL: revistainveniendi@usantotomas.edu.co

estudio del impacto fiscal de las leyes que impliquen gastos públicos; la Corte Constitucional cuando efectuó el control previo especial de constitucionalidad de la ley estatutaria que regula el procedimiento de elección de parlamentarios andinos $^{8}$, estableció que la incorporación del estudio del impacto fiscal a la citada ley, no era obligatoria, como quiera que la constitucionalidad de la misma, no podía quedar sometida al cumplimiento de requisitos de orden económico a cargo del Gobierno, y a que las ponencias para los dos debates en la Cámara de Representantes fueron presentadas antes de la fecha de promulgación de la ley 819 de 2003, norma que obliga el estudio del referenciado impacto fiscal. Pero si bien la citada decisión de la Corte Constitucional fue sana, en la actualidad no existe certeza de la fuente de financiamiento de los gastos que generara dicha ley, es mas, antes del 15 de junio de 2009 el Gobierno Nacional ha debido presentar a las Comisiones Económicas del Senado y de la Cámara de Representantes, el Marco Fiscal de Mediano Plazo, sin que para esta fecha existiese el mencionado estudio de impacto fiscal $^{9}$.

b) La inexistencia del un Régimen Electoral Uniforme en los Países andinos, que regule los procedimientos electorales andinos.

\footnotetext{
Ministerio de Hacienda y Crédito Público, en cualquier tiempo durante el respectivo trámite en el Congreso de la República, deberá rendir su concepto frente a la consistencia de lo dispuesto en el inciso anterior. En ningún caso este concepto podrá ir en contravía del Marco Fiscal de Mediano Plazo. Este informe será publicado en la Gaceta del Congreso. Los proyectos de ley de iniciativa gubernamental, que planteen un gasto adicional o una reducción de ingresos, deberá contener la correspondiente fuente sustitutiva por disminución de gasto o aumentos de ingresos, lo cual deberá ser analizado y aprobado por el Ministerio de Hacienda y Crédito Público."

${ }^{8}$ CORTE CONSTITUCIONAL, Sentencia C-502/07, 4 de julio de 2007, M.P Manuel José Cepeda Espinosa

${ }^{9}$ Ver al respecto el Articulo $1^{\text {o }}$ de la Ley 819 de 2003
} 


\section{REVISTA VIRTUAL VIA INVENIENIDI ET IUDICANDI \\ "CAMINO DEL HALLAZGO Y DEL JUICIO"}

http://viei.usta.edu.co/ E-MAIL: revistainveniendi @usantotomas.edu.co

De la lectura de las normas internacionales que regulan a la Comunidad Andina de Naciones, se deduce que en la Comunidad Andina se aspira a dictar un régimen electoral uniforme para la elección de todos los representantes al Parlamento Andino, independientemente de su país de origen. Sin embargo, hasta ahora ese propósito no se ha cristalizado. Para el efecto, es preciso hacer referencia prioritariamente, al Tratado de Elecciones Directas Universales de Parlamentarios Andinos, el cual establece la obligación de los Estados integrantes de la Comunidad, de gestionar un Régimen Electoral Uniforme. Dicha normatividad internacional, ha sido desarrollada en la ley estatutaria que reglamento la elección directa de parlamentarios andinos en Colombia, la cual prevé en el Artículo $2^{\circ}$ que mientras se establece un régimen electoral uniforme, el sistema de elección de los Representantes ante el Parlamento Andino se regirá de acuerdo con la legislación electoral colombiana.

Es necesario elaborar y poner en marcha un proyecto que conduzca a sentar las bases normativas de las elecciones directas y universales de los Parlamentarios Andinos en los cuatro países del Área. De ahí la importancia de elaborar y aprobar una normativa supranacional de cumplimiento forzoso y aplicado a todos los países de la Comunidad, que regule los procesos electivos andinos.

En este sentido, se debe potenciar el papel del Consejo Electoral Andino - CEA, insertado al Sistema Andino de Integración mediante la Decisión 551 de la 


\section{REVISTA VIRTUAL VIA INVENIENDI ET IUDICANDI}

"CAMINO DEL HALLAZGO Y DEL JUICIO"

http://viei.usta.edu.co/ E-MAIL: revistainveniendi@usantotomas.edu.co

Comunidad Andina ${ }^{10}$, como órgano encargado de liderar la proyección del documento referenciado. Para el efecto, es preciso establecer que dicho Consejo, tiene entre sus atribuciones, emitir opinión ante el Consejo Andino de Ministros de Relaciones Exteriores y la Secretaría General de la Comunidad Andina en los ámbitos de su competencia, cuando así se lo requieran; elaborar y recomendar la aprobación del Estatuto Electoral Andino y sus reformas; auspiciar mecanismos de cooperación horizontal y asistencia técnica entre los órganos electorales de la región; supervisar y observar los procesos de elección directa de los parlamentarios andinos; sugerir medidas para el perfeccionamiento de la legislación electoral interna relacionada con la elección de los Parlamentarios andinos en cada País Miembro; entre otras.

d) No superación del déficit democrático que atraviesa el proceso andino de integración ${ }^{11}$

A la fecha, se observa que los Ejecutivos de los Estados Andinos, de alguna manera absorben todas las atribuciones de gestión del proceso de integración andino, ejerciéndolas en virtud de su competencia de manejar las relaciones internacionales, en otras palabras, se aprecia que dentro del contexto de los

\footnotetext{
${ }^{10}$ Ver Decisión 551 del 2003. Dicho instrumento consagra la creación del Consejo Electoral Andino, como miembro del Sistema Andino de Integración, el cual estará conformado por los titulares de los órganos electorales de los Países Miembros de la Comunidad Andina.

11 Para el estudio sobre el Déficit Democrático en la Integración se tomó como base el documento “ La Integración Andina y el reto democrático de su desarrollo institucional "elaborado por Mauricio Salcedo para la conferencia dictada con ese título en el seminario "Integración Andina en el la Coyuntura Actual" Universidad Javeriana y Fundación Konrad Adenauer, Agosto 29 de 2001.
} 
http://viei.usta.edu.co/ E-MAIL: revistainveniendi@usantotomas.edu.co

Estados Andinos se presenta una gran concentración en las autoridades ejecutivas del proceso integracionista de diseñar políticas, implementarlas y ejercer el control de su aplicación, en razón a la debilidad de un ente evaluador que garantice su adecuada ejecución. Esta última función debe ser realizada por un órgano autónomo fuerte, con capacidad vinculante en sus pronunciamientos, y que garantice la debida aplicación de las directrices integracionistas, lo cual sólo podrá darse cuando el Parlamento Andino goce de la legitimidad que le otorga tener miembros designados por vía de elección popular. 